\title{
Twenty-Eight-Day Mortality of Blunt Traumatic Brain Injury and Co-Injuries Requiring Mechanical Ventilation
}

\author{
Bojan Jovanovic $^{b, c}$ Zoka Milan ${ }^{e}$ Olivera Djuric ${ }^{a} \quad$ Ljiljana Markovic-Denic $^{a}$ \\ Aleksandar Karamarkovic $^{\text {b, d }}$ Pavle Gregoric ${ }^{\text {b, d }}$ Krstina Doklestic ${ }^{\text {b, d }}$ \\ Jovana Avramovic c Jelena Velickovic ${ }^{\text {b,c }}$ Vesna Bumbasirevic ${ }^{\text {b, } c}$ \\ ${ }^{a}$ Institute of Epidemiology of the ${ }^{b}$ Faculty of Medicine, University of Belgrade, and ${ }^{\mathrm{C} C e n t r e ~ f o r ~ A n a e s t h e s i o l o g y ~ a n d ~}$ \\ ${ }^{\mathrm{d}}$ Clinic for Emergency Surgery, Clinical Centre of Serbia, Belgrade, Serbia; ${ }^{\mathrm{e}}$ King's College Hospital, London, UK
}

\section{Key Words}

Brain injury · Polytrauma $\cdot$ Mortality $\cdot$ Critical care .

Pneumonia

\begin{abstract}
Objective: This paper aims to assess the impact of co-injuries and consequent emergency surgical interventions and nosocomial pneumonia on the 28-day mortality of patients with severe traumatic brain injuries (TBIs). Subjects and Methods: One hundred and seventy-seven patients with TBI admitted to the emergency trauma intensive care unit at the Clinical Center of Serbia for more than $48 \mathrm{~h}$ were studied over a 1-year period. On admission, the Glasgow Coma Scale (GCS), Injury Severity Score (ISS) and Acute Physiology and Chronic Health Evaluation II score (APACHE II) were calculated. At admission, an isolated TBI was recorded in 45 of the patients, while 44 had three or more co-injuries. Results: Of the 177 patients, $78(44.1 \%)$ died by the end of the 28-day follow-up period. They had a significantly higher ISS score ( 25 vs. 20 ; $p=0.024)$ and more severe head $(p=0.034)$ and chest $(p=$ 0.013 ) injuries compared to those who survived. Nonsurvivors had spent more days on mechanical ventilation (9.5 vs. $8 ; p=0.041)$ and had a significantly higher incidence of ven-
\end{abstract}

tilator-associated pneumonia (VAP) than survivors (67.9 vs. 40.4\%; $\mathrm{p}<0.001$ ). A high Rotterdam CT score (OR 2.062; $\mathrm{p}<$ 0.001 ) and a high APACHE II score (OR 1.219; $p<0.001$ ) were identified as independent predictors of early TBI-related mortality. Conclusion: Patients who had TBI with a high Rotterdam score and a high APACHE II score were at higher risk of 28-day mortality. VAP was a very common complication of TBI and was associated with an early death and higher mortality in the subgroup of patients with a GCS $\leq 8$.

(c) 2016 S. Karger AG, Basel

\section{Introduction}

Severe traumatic brain injury (TBI) is a heterogeneous disease with respect to its causes, severity, pathology and prognosis [1]. It contributes to a large proportion of death, disability and cost related to injury treatment worldwide [2,3]. While the incidence and causes of TBI vary between countries, mortality remains high worldwide [4].

The incidence of polytrauma remains high in many countries, particularly in older populations [4]. Severe TBIs are usually associated with injuries of other body

\begin{tabular}{ll}
\hline KARGER & $\begin{array}{l}\text { ( ) 2016 S. Karger AG, Basel } \\
1011-7571 / 16 / 0255-0435 \$ 39.50 / 0 \quad \text { Karger }\end{array}$ \\
$\begin{array}{l}\text { E-Mail karger@karger.com } \\
\text { www.karger.com/mpp }\end{array}$ & $\begin{array}{l}\text { Thisis an Open Access article licensed under the terms of the } \\
\text { Creative Commons Attribution-NonCommercial 3.0 Un- } \\
\text { ported license (CC BY-NC) (www.karger.com/OA-license), } \\
\text { applicable to the online version of the article only. Distribu- } \\
\text { tion permitted for non-commercial purposes only. }\end{array}$
\end{tabular}

Bojan Jovanovic

Emergency Centre, Clinical Centre of Serbia

Pasterova 2

RS-11000 Belgrade (Serbia)

E-Mail bjovanovic@ outlook.com 
regions [5], and emergency surgical interventions are often required. This leads to prolonged recovery periods, prolonged stays in intensive care unit (ICU) and longer durations of mechanical ventilation (MV) [6], all of which inevitably influence the incidence of in-hospital complications. In addition, age and comorbidities, such as cardiac and metabolic diseases, can often influence the course of patient treatment.

Patients with severe injuries are at high risk of acquiring a nosocomial infection, particularly hospital-acquired pneumonia and ventilator-associated pneumonia (VAP), due to prolonged MV [7]. Moreover, VAP significantly increases the stay in the ICU and hospital, and is directly linked to a worse outcome [8]. Hospital-acquired pneumonia can even influence the global outcome after 5 years following severe TBI hospital-acquired pneumonia [9$11]$.

Therefore, we investigated the impact of extracranial injuries, emergency surgical interventions and pneumonia due to MV on the 28-day mortality of patients with TBI and identified which admission variables were independent predictors of an early death following TBI requiring MV.

\section{Subjects and Methods}

\section{Design and Sample}

A prospective cohort study was conducted at the Emergency Department, Clinical Center of Serbia, which is the sole adult tertiary care trauma center serving the southern and central areas of Serbia. The inclusion criteria were: (a) all patients were admitted to the ICU between January 2013 and December 2013 and (b) they were diagnosed with TBI, either isolated or with one or more extracranial injuries and required MV. The exclusion criteria were: (a) $<18$ years of age; (b) recorded gastric aspiration; (c) antibiotic therapy in the previous 90 days; (d) recent hospitalization; (e) residence in a nursing home or extended care facility; (f) home therapy (including antibiotics and wound care); and (g) underlying malignancy. The study was approved by University of Belgrade, Medical School Institutional Review Board.

\section{Subjects}

The study population comprised 177 patients (142 males and 34 females) with TBI; 45 with isolated TBI and 132 with additional injuries. Fifty-four patients were $\geq 65$ years old, and 82 presented with comorbidities, among which cardiac disease was the most common.

\section{Data Variables and Outcomes}

On admission, data regarding the patients' sociodemographic characteristics, comorbidities and the distribution of trauma by system were recorded. The Glasgow Coma Scale (GCS), Acute Physiology and Chronic Health Evaluation II score (APACHE II), and trauma scores [Abbreviated Injury Scale (AIS) and Injury Se-
Table 1. General and clinical characteristics of patients with traumatic brain injury $(\mathrm{n}=177)$

$\begin{array}{lc}\text { Male } & 142(80.2) \\ \text { Female } & 35(19.8) \\ \text { Median age (IQR) } & 50(37) \\ 18-25 \text { years } & 27(15.3) \\ 26-45 \text { years } & 40(22.6) \\ 46-65 \text { years } & 56(31.6) \\ >65 \text { years } & 54(30.5) \\ \text { Number of comorbidities } & \\ 0 & 95(53.7) \\ 1 & 50(28.2) \\ 2 & 19(10.7) \\ \geq 3 & 13(7.3) \\ \text { Type of comorbidities } & 82(46.3) \\ \text { Cardiac disease } & 50(28.2) \\ \text { Diabetes mellitus } & 18(10.2) \\ \text { Chronic alcohol abuse } & 11(6.2) \\ \text { Epilepsy } & 9(5.1) \\ \text { Chronic renal failure } & 9(5.1) \\ \text { Chronic liver disease } & 7(4.0) \\ \text { Chronic obstructive pulmonary disease } & 4(2.3) \\ \text { Immunodeficiency } & 4(2.3) \\ \text { Drug addiction } & 4(2.3) \\ \text { Asthma } & 2(1.1) \\ \text { Psychiatric disease } & 2(1.1) \\ \text { Hematologic disease } & 1(0.6) \\ \text { Restrictive lung disease } & 1(0.6) \\ \text { Neurologic disease } & 1(0.6) \\ \text { Endocrine disease } & 1(0.6) \\ \text { Median APACHE II (IQR) } & 15(9) \\ \text { Median GCS (IQR) } & 8(6) \\ \text { GCS } \leq 8 & 46(26.0) \\ \text { GCS 9-12 } & 26(14.7) \\ \text { GCS } \geq 13 & \end{array}$

Values are n (\%), unless otherwise indicated.

verity Score (ISS)] were calculated on admission (B.J. and J.A.). The GCS was calculated at the first contact with medical services before intubation and sedation (before hospital admission or at admission). The same value was added to the APACHE II score if the patients were intubated and sedated at ICU admission. The Marshall and Rotterdam scores were calculated (B.J. and P.G.). Data concerning surgical interventions, clinical, laboratory and radiographic data were reviewed daily from the patients' medical documentation. Chest X-rays were interpreted (K.D. and V.B.). All patients were managed following the standardized protocol of the American Thoracic Society [12] if pneumonia was suspected. Our institution implements the Brain Trauma Foundation treatment guidelines for TBI. We also have a restrictive transfusion practice due to recommendations with a restrictive hemoglobin transfusion trigger of $<8 \mathrm{~g} / \mathrm{dl}$ and transfusion decisions guided by risk and benefit analysis for each patient with emergency neurosurgical intervention, whose efficacy has been studied before $[13,14]$. 


\section{Definitions}

TBI was defined as primary blunt injury induced by mechanical force such as traffic and motorcycle accidents that caused temporary or permanent neurological dysfunction. TBI was diagnosed and estimated by clinical examinations of the level of consciousness using scoring systems, CT imaging and the assessment of other vital parameters such as intracranial pressure.

The ISS is an anatomical scoring system that provides an overall score for patients with multiple injuries. Each injury is assigned an AIS for one of six body regions: head, face, chest, abdomen, extremities and external. Only the highest AIS score in each body region was used. The scores of the three most severely injured body regions were squared and added together to produce the ISS score. The GCS is a neurological scale that aims to record the level of conscious state of a person for initial as well as subsequent assessment. The scale is composed of three tests: eye, verbal and motor responses. The APACHE II is a severity-of-disease classification system applied within $24 \mathrm{~h}$ of admission of a patient in an ICU. The Marshall CT classification score is a descriptive tool with three variables: presence of mass lesion, status of perimesencephalic cisterns and degree of midline shift in six categories (diffuse injury I to IV, evacuated mass lesion and nonevacuated mass lesion). The Rotterdam CT score is a six-month mortality outcome prediction score using the following variables: basal cisterns, midline shift, epidural mass lesion and intraventricular blood or traumatic subarachnoid hemorrhage.

The VAP is diagnosed when new, persistent pulmonary infiltrates, not otherwise explained, appear on chest X-rays $>48 \mathrm{~h}$ after admission in the ICU and when there are one systemic or two pulmonary criteria. The systemic criteria were: fever $>38^{\circ} \mathrm{C}$, leucopenia (count $<4,000$ white blood cells $/ \mathrm{mm}^{3}$ ) or leucocytosis (count $>12,000$ white blood cells $/ \mathrm{mm}^{3}$ ); for adults $>70$ years, the systemic criteria also included altered mental status of no other recognized cause. The pulmonary criteria were: new onset of purulent sputum (or a change in the character of the sputum, increased respiratory secretions or increased suctioning requirements), worsening gas exchange (desaturations, increased oxygen requirements or increased ventilator demand), new-onset or worsening cough, and dyspnea or tachypnea and rales or bronchial breath sounds [15]. A positive chest X-ray was defined as a progressive or new infiltrate, consolidation, pleural effusion or cavitation. Sputum change is defined as the new onset of purulent sputum or a change in the character of the sputum [15].

\section{Statistical Analysis}

For continuous variables, the Kolmogorov-Smirnov test was used to assess the assumption of normality. Based on this, continuous data are presented as the median with the interquartile range (IQR), and a comparison between survivors and nonsurvivors was performed using the nonparametric Mann-Whitney $U$ test. Categorical data are presented as numbers and percentages and were compared using Pearson's $\chi^{2}$ test or Fisher's exact test. Logistic regression was performed to investigate which of the admission variables were significant predictors of 28-day mortality. Variables regarding patients' characteristics (age, sex and comorbidities), injury characteristics and severity (type and number of injuries, injured body regions, AIS and ISS), number and localization of surgical procedures and clinical condition on admission (GCS, CT scan scores and APACHE II) were first analyzed in univariate logistic regression analysis. Variables that were associated with 28 -day mortality at a significance level $<0.1$ in the univariate
Table 2. Trauma distribution and severity by body region, surgical procedures and outcomes in patients with traumatic brain injury

Injuries

Isolated TBI

$45(25.4)$

Combined TBI

$\mathrm{TBI}+1$

$\mathrm{TBI}+2$

$56(31.6)$

$\mathrm{TBI}+\geq 3$

$32(18.1)$

44 (24.9)

Injury by system

Face

$76(42.9)$

Thorax

$73(41.2)$

Abdomen

29 (16.4)

Extremities/pelvis

$64(36.2)$

Spine

29 (16.4)

Severity of injury

AIS $_{\text {Head }}$ score $\geq 3$

$119(67.2)$

AIS $_{\text {Face }}$ score $\geq 3$

45 (25.4)

AIS $_{\text {Thorax }}$ score $\geq 3$

$39(22.0)$

AIS $_{\text {Abdomen }}$ score $\geq 3$

$16(9.0)$

AIS $_{\text {Extremities/Pelvis }}$ score $\geq 3$

$43(24.3)$

ISS

AIS $_{\text {Spine }}$ score $\geq 3$

$<9$

$21(11.9)$

9-15

$32(18.1)$

$16-24$

$52(29.4)$

25-75

$72(40.7)$

$20(20)$

Median ISS (IQR)

123 (69.6)

Number of surgeries

0

1

$54(30.4)$

$86(48.6)$

$29(16.4)$

$\geq 3$

$8(4.6)$

$61(34.5)$

$38(62.3)$

$6(9.8)$

4 (6.6)

$3(4.9)$

4 (6.6)

Subtemporal decompression

Elevation and debridement of depressed skull fractures

$6(9.8)$

\section{Clinical outcomes}

Median ICU LOS (IQR), days

$11(9)$

Median MV (IQR), days

$9(6)$

VAP

$93(52.5)$

28-day mortality

$78(44.1)$

Values are expressed as $\mathrm{n}(\%)$, unless otherwise indicated. LOS = Length of stay.

analysis were entered into a multivariate model, and stepwise logistic regression was performed. ORs with $95 \%$ CIs were computed, and the Hosmer-Lemeshow goodness-of-fit test was performed to assess overall model fit. Measures of discrimination (Nagelkerke $\mathrm{r} 2$ and area under the receiver operating characteristic curve) were 
Table 3. Association of injury distribution and severity, surgeries and clinical outcomes with 28-day mortality in patients with traumatic brain injury

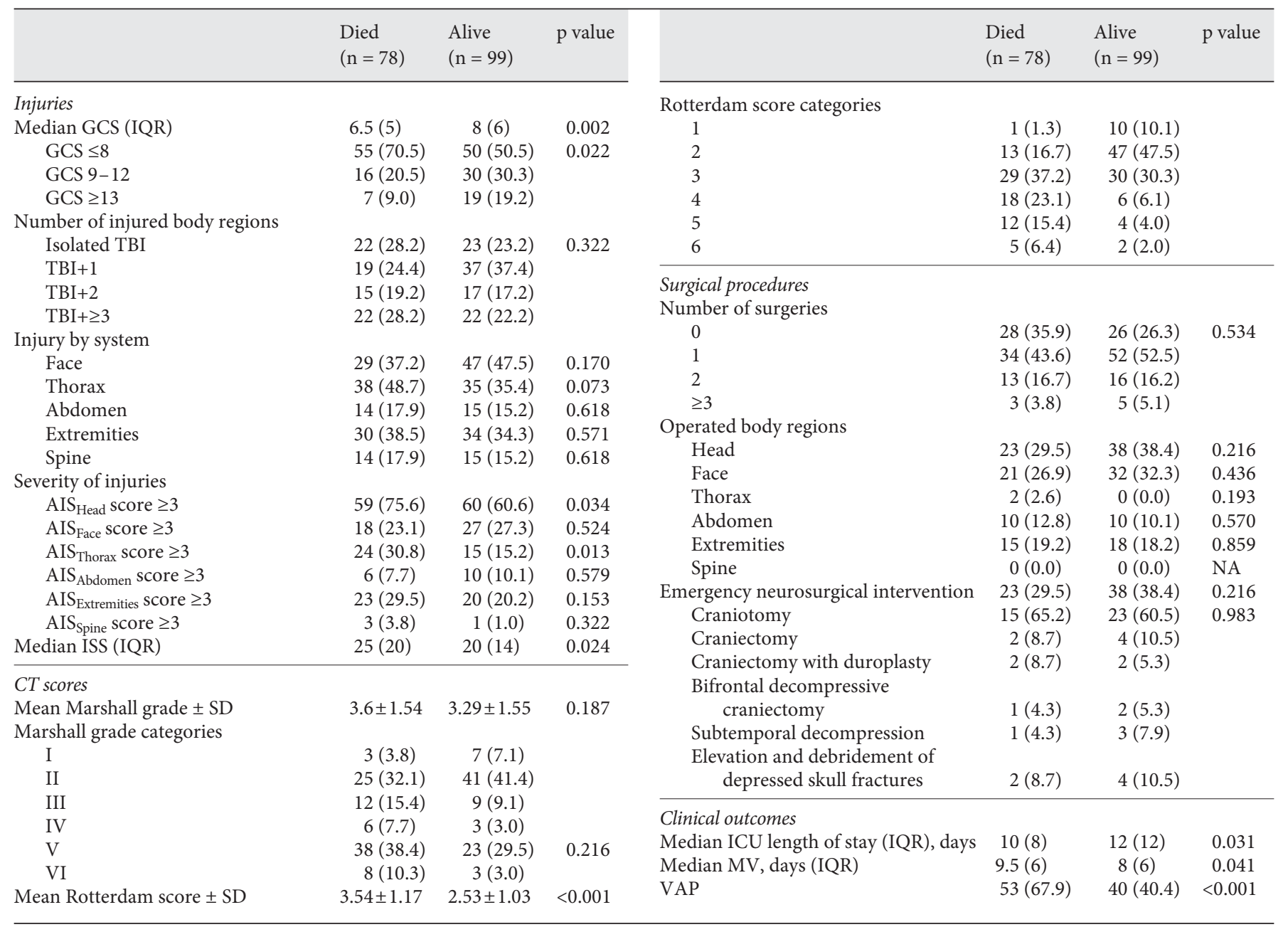

Values are expressed as $\mathrm{n}(\%)$, unless otherwise indicated. LOS = Length of stay; NA = not applicable.

calculated for all regression models. All statistical tests were twosided and were performed at a 5\% significance level. Statistical analyses were performed using SPSS version 20.0 software (SPSS Inc., Chicago, Ill., USA).

\section{Results}

\section{Patients' Characteristics}

The general and clinical characteristics of the study population are summarized in table 1 . The median age was 50 years [IQR = 37 (range: $19-75)$ ].

Injury-related characteristics, undertaken operative procedures and clinical outcomes of the study population during the ICU treatment are shown in table 2 . The
TBI plus one additional injury was the most common injury pattern: 56 (31.6\%); TBI alone: 45 (25.4\%) and TBI plus three or more additional injuries: 44 (24.9\%). The face and thorax were the most common additional systems injured, encountered in 76 (42.9\%) and 73 (41.9\%) of the patients, respectively. Considering the severity of the injuries, the head was the most severely injured body region because $119(67.2 \%)$ of patients had an AIS head score $\geq 3$. One hundred and twenty-three $(69.5 \%)$ were subject to one or more surgical procedure, most commonly only one $(48.6 \%)$, while emergency neurosurgery interventions were done in 61 (34.5\%) patients. The most common one was craniotomy in 38 $(62.3 \%)$ patients. 
Table 4. Predictors of traumatic brain injury-related 28-day mortality

\begin{tabular}{|c|c|c|c|c|c|c|}
\hline & \multicolumn{3}{|c|}{ Univariate } & \multicolumn{3}{|c|}{ Multivariate } \\
\hline & OR & $95 \% \mathrm{CI}$ & $\mathrm{p}$ value & OR & $95 \% \mathrm{CI}$ & $\mathrm{p}$ value \\
\hline Age & 1.032 & $1.016-1.049$ & $<0.001$ & & & \\
\hline GCS $<8$ & 2.831 & $1.462-5.482$ & 0.002 & & & \\
\hline Rotterdam CT score & 2.294 & $1.663-3.163$ & $<0.001$ & 2.062 & $1.448-2.937$ & $<0.001$ \\
\hline Comorbidities & 1.969 & $1.073-3.612$ & 0.029 & & & \\
\hline Cardiac disease & 3.302 & $1.672-6.519$ & 0.001 & & & \\
\hline $\mathrm{AIS}_{\text {Head }}$ score $\geq 3$ & 2.413 & $1.224-4.758$ & 0.011 & & & \\
\hline AIS $_{\text {Thorax }}$ score $\geq 3$ & 2.208 & $1.073-4.541$ & 0.031 & & & \\
\hline ISS & 1.033 & $1.009-1.058$ & 0.007 & & & \\
\hline APACHE II & 1.249 & $1.161-1.343$ & $<0.001$ & 1.219 & $1.132-1.313$ & $<0.001$ \\
\hline
\end{tabular}

Ninety-three patients (52.5\%) had developed VAP during the ICU stay. The median days spent in the ICU and on MV were 11 and 9 days, respectively.

\section{Comparison of Survivors and Nonsurvivors}

Up to the 28th day of follow-up, 78 (44.1\%) patients died: 60 males and 18 females. The injury- and surgeryrelated characteristics, as well as the frequency of clinically relevant outcomes, of the survivors and nonsurvivors are summarized in table 3 . There was a significant difference in the ISS score $(\mathrm{p}=0.024)$, ICU length of stay $(\mathrm{p}=0.031)$, length of MV $(\mathrm{p}=0.041)$ and frequency of $\operatorname{VAP}(\mathrm{p}<0.001)$ between the survivors and nonsurvivors (table 3). Patients who died before the 28th ICU day had a significantly lower initial GCS ( $\mathrm{p}=0.02)$. They also had substantially more severe head and thoracic injuries and were more severely injured as indicated by a higher ISS (median: 25 vs. $20, \mathrm{p}=0.024$ ). The Rotterdam CT score was significantly higher in patients who died (mean: 3.54 vs. $2.53, \mathrm{p}<0.001)$.

Nonsurvivors spent more days on MV (median: $9.5 \mathrm{vs.}$ 8 days, $p=0.041$ ) and more frequently had VAP than survivors (67.9 vs. $40.4 \%$ ). Patients who died spent fewer days in the ICU than those who survived (median: 10 vs. 12 days, respectively; $\mathrm{p}=0.031$ ).

\section{Predictors of Early TBI-Related Mortality}

Univariate logistic regression analysis showed that age, GCS, Rotterdam CT score, the presence of a comorbidity or cardiac disease, an AIS score for the head and thorax $\geq 3$, and ISS and APACE II scores were significantly associated with the 28-day mortality following TBI. However, only the Rotterdam score and APACHE II remained significant predictors of early TBI-related death in the multivariate logistic model. Specifically, patients who had TBI and admission to the ICU presented with a higher Rotterdam score or had a higher APACHE II score, thus 2.1 and 1.2 higher odds for experiencing a fatal outcome, respectively. The Nagelkerke $\mathrm{r} 2$ for the final model was 0.439 , and the area under the receiver operating characteristic curve was 0.845 (95\% CI 0.787-0.903; $\mathrm{p}<0.001)$. The model fit the data properly since the Hosmer-Lemeshow test was nonsignificant $(\mathrm{p}=0.126)$. The results of the univariate and multivariate logistic regression analyses are shown in table 4.

The impact of VAP on mortality rates in patents with different GCS and APACHE II scores are presented in figure 1 and 2, respectively. Patients who developed VAP had almost two-fold higher mortality than those who did not, even in the group with a GCS $\leq 8$ ( $25.5 \%$ vs. 47.6$)$, and lower APACHE II scores. Mortality in patients with VAP was two times higher compared with those without VAP in a group of patients with a GCS $>8(p=0.067)$.

\section{Discussion}

The TBI-related 28-day mortality rate was $44.1 \%$, which is slightly higher compared to other studies [16, 17]. In this study, the number of co-injuries was significant due to influence of attributive mortality in TBI. This finding is consistent with the overall mortality rate of patients with severe TBI worldwide, which has not decreased since 1990 despite the introduction of evidencebased guidelines for the management of TBI [17]. In our study, the median age of 50 years, and $28.2 \%$ of the patients with cardiac disease, is consistent with a significant shift towards the older patients as had been observed in 


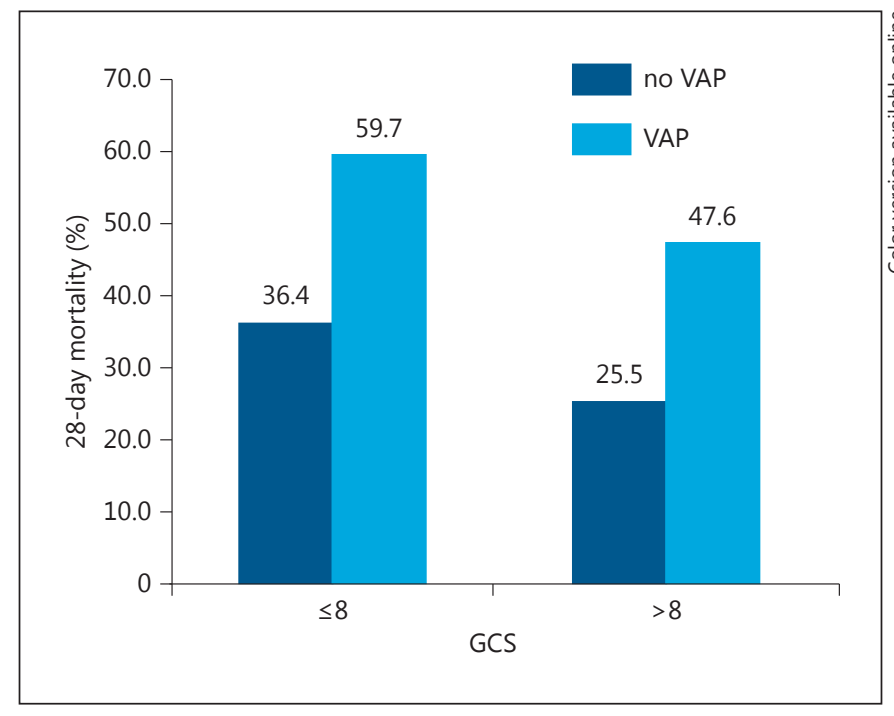

Fig. 1. Mortality rates according to the presence of VAP and GCS category.

other studies $[17,18]$, and a high incidence of comorbidities has a negative influence on the outcome following TBI [4]. However, younger patients had a higher injury score due to higher incidence of traffic accidents in our country (car, motorcycle).

Almost $75 \%$ of the patients in our study had one or more co-injuries, predominantly to the face, thorax and extremities, a common injury pattern in our country. Moreover, two thirds of the patients had severe brain injury with an AIS $\geq 3$. Thoracic trauma with an AIS of $\geq 3$ influenced the outcome. Severe rib fractures were usually associated with pulmonary contusions that influenced the diagnostic and therapeutic strategies during initial treatment [17]. The overall severity of trauma was greater in patients who died during the first 28-day period (median ISS, 25) than in those who survived (median ISS, 20). However, trauma scoring systems are suboptimal for the prediction of outcome in TBI patients [14]. Patients presenting with a lower GCS on admission had a higher mortality rate.

In this study, $52.5 \%$ high incidence of VAP in the TBI population could be due to tracheal colonization, which had been identified as a risk factor for the development of pneumonia in patients with TBI. Consequently, the injury might induce immunity suppression [19-23]. In head-trauma patients, the consequences of early-onset pneumonia are particularly deleterious because they occur during the most important days of care of TBI, and early-onset pneumonia must be properly prevented. Hence, patients with a higher GCS and co-injuries spent

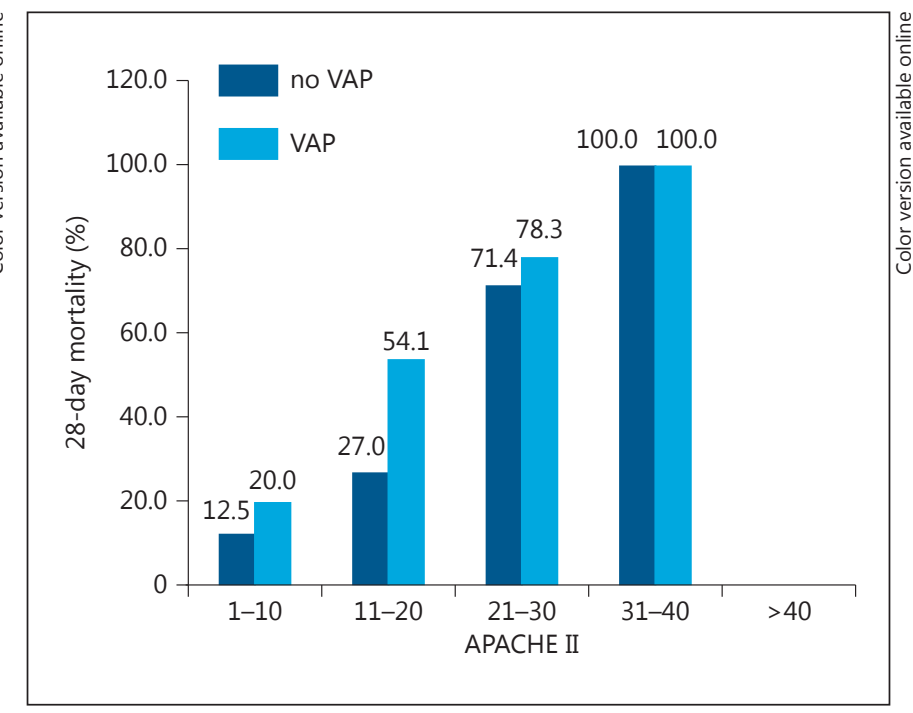

Fig. 2. Mortality rates according to the presence of VAP and APACHE II score category.

more days on MV, leading to a higher incidence of VAP, as shown in this study.

The severity of trauma reflected the median ICU stay, which was lower for nonsurvivors, with almost equal days on $\mathrm{MV}$, indicating no MV-free days. In contrast, survivors had more ICU days due to the recovery period with MV-free days [24].

In our study, the Rotterdam CT score appeared to be a significant independent predictor of 28-day mortality in severe TBI patients in multivariate analysis. Moreover, the prognostic values of the Marshall and Rotterdam CT scores in our study were similar, as described earlier [25]. Although the GCS was not independently associated with 28 -day mortality in our study, the mortality rate was almost two-fold higher in patients with a GCS $>8$, indicating that the GCS is a less reliable predictor of fatal outcome.

\section{Conclusion}

In this study, patients with severe TBI and associated injuries had a high mortality rate. The severity of head and chest injuries had a significant impact on the 28-day mortality, but the number and type of surgical interventions did not. This subgroup of patients with TBI and chest co-injuries was at very high risk of the development of VAP. Patients with a higher Rotterdam score or a high APACHE II score had 2.1 and 1.2 higher odds to experience a fatal outcome, respectively. 


\section{Acknowledgement}

This work was supported by the Ministry of Science and Technological Development of Serbia, contract No. 175046, 2011-2014.

\section{Disclosure Statement}

The authors have no conflicts of interest to disclose.

\section{References}

1 Kristiansen T, Lossius HM, Rehn M: Epidemiology of trauma: a population-based study of geographical risk factors for injury deaths in the working-age population of Norway. Injury 2014;45:23-30.

2 McGarry LJ, Thompson D, Millham FH, et al: Outcomes and costs of acute treatment of traumatic brain injury. J Trauma 2002;53: 1152-1159.

$\checkmark 3$ Masson F, Thicoipe M, Aye P, et al: Epidemiology of severe brain injuries: a prospective population-based study. J Trauma 2001;51: 481-489.

4 Roozenbeek B, Maas AI, Menon DK: Changing patterns in the epidemiology of traumatic brain injury. Nat Rev Neurol 2013;9:231-236.

$\checkmark 5$ Maas AI, Stocchetti N, Bullock R: Moderate and severe traumatic brain injury in adults. Lancet Neurol 2008;7:728-741.

6 Corrigan JD, Selassie AW, Orman JA: The epidemiology of traumatic brain injury. J Head Trauma Rehabil 2010;25:72-80.

7 Fiebich BL, Akter S, Akundi RS: The two-hit hypothesis for neuroinflammation: role of exogenous ATP in modulating inflammation in the brain. Front Cell Neurosci 2014;8:260272.

$>8$ Rello J, Ausina V, Ricart M, et al: Nosocomial pneumonia in critically ill comatose patients: need for a differential therapeutic approach. Eur Respir J 1992;5:1249-1253.

$>9$ Dikmen SS, Machamer JE, Powell JM, et al: Outcome 3-5 years after moderate to severe traumatic brain injury. Arch Phys Med Rehabil 2003;84:1449-1457.
10 Kesinger MR, Kumar RG, Wagner AK, et al: Hospital-acquired pneumonia is an independent predictor of poor global outcome in severe traumatic brain injury up to 5 years after discharge. J Trauma Acute Care Surg 2015;78: 396-402.

11 Büki A, Czeiter E, Kovács N, et al: Geriatric traumatic brain injury in Hungary and Eastern Europe. Curr Transl Geriatr Exp Gerontol Rep 2012;1:159-166.

12 Niederman MS, Craven D, Bonten MJ, et al: Guidelines for the management of adults with hospital-acquired, ventilator-associated, and healthcare-associated pneumonia. Am J Respir Crit Care Med 2005;171:388-416.

13 Al-Faris L, Al-Fares AR, Abdul Malek K, et al: Blood transfusion practice in critically ill patients: a single institutional experience. Med Princ Pract 2012;21:560-565.

14 Gruenbaum SE, Ruskin KJ: Red blood cell transfusion in neurosurgical patients. Curr Opin Anaesthesiol 2014:470-473.

15 Canadian Critical Care Trials Group: A randomized trial of diagnostic techniques for ventilator-associated pneumonia. N Engl J Med 2013;355:2619-2630.

16 Lepelletier D, Roquilly A, Demeure dit latte $\mathrm{D}$, et al: Retrospective analysis of the risk factors and pathogens associated with early-onset ventilator-associated pneumonia in surgical-ICU head-trauma patients. J Neurosurg Anesthesiol 2010;22:32-37.

17 Zygun DA, Zuege DJ, Boiteau PJ, et al: Ventilator-associated pneumonia in severe traumatic brain injury. Neurocrit Care 2006;5: 108-114.
18 Maas AI, Stocchetti N, Bullock R: Moderate and severe traumatic brain injury in adults. Lancet Neurol 2008;7:728-741.

19 Contentin L, Ehrmann S, Giraudeau B: Heterogeneity in the definition of mechanical ventilation duration and ventilator-free days. Am J Respir Crit Care Med 2014;15:9981002.

20 Hsieh AH, Bishop MJ, Kubilis PS, et al: Pneumonia following closed head injury. Am Rev Respir Dis 1992;146:290-294.

21 Ewig S, Torres A, El-Ebiary M, et al: Bacterial colonization patterns in mechanically ventilated patients with traumatic and medical head injury. Incidence, risk factors, and association with ventilator-associated pneumonia. Am J Respir Crit Care Med 1999;159: 188-198.

-22 Berrouane Y, Daudenthun I, Riege B: Early onset pneumonia in neurosurgical intensive care unit patients. J Hosp Infect 1998;40:275280

23 Pories SE, Gamelli RL, Mead PB, et al: The epidemiologic features of nosocomial infections in patients with trauma. Arch Surg 1991; 126:97-99.

24 Stein SC, Georgoff P, Meghan S, et al: 150 years of treating severe traumatic brain injury: a systematic review of progress in mortality. J Neurotrauma 2010;27:1343-1353.

25 Deepika A, Prabhuraj AR, Saikia A, et al: Comparison of predictability of Marshall and Rotterdam CT scan scoring system in determining early mortality after traumatic brain injury. Acta Neurochir 2015;157:2033-2038. 